\title{
BMJ Open Comparing mental distress and help- seeking among first-year medical students in Norway: results of two cross-sectional surveys 20 years apart
}

\author{
Nora Ruud (D) , ${ }^{1}$ Lise Tevik Løvseth, ${ }^{2}$ Karin Isaksson Ro, ${ }^{3}$ Reidar Tyssen ${ }^{1}$
}

To cite: Ruud N, Løvseth LT, Isaksson Ro K, et al. Comparing mental distress and help-seeking among first-year medical students in Norway: results of two cross-sectional surveys 20 years apart. BMJ Open 2020;10:e036968. doi:10.1136/ bmjopen-2020-036968

- Prepublication history for this paper is available online. To view these files, please visit the journal online (http://dx.doi org/10.1136/bmjopen-2020036968).

Received 04 April 2020 Revised 16 June 2020 Accepted 06 July 2020

\section{Check for updates}

C Author(s) (or their employer(s)) 2020. Re-use permitted under CC BY-NC. No commercial re-use. See rights and permissions. Published by BMJ.

${ }^{1}$ Department of Behavioural Sciences in Medicine, Faculty of Medicine, University of Oslo, Oslo, Norway

${ }^{2}$ Department of Research and Development, Department of Psychiatry, St Olav University Hospital, Trondheim, Norway ${ }^{3}$ LEFO, Institute for Studies of the Medical Profession, 0slo, Norway

Correspondence to

Nora Ruud;

nora.ruud@studmed.uio.no

\section{ABSTRACT}

Objective To investigate any changes in mental distress levels over 20 years among medical students, as well as the clinical importance of these changes.

Design Two cross-sectional surveys 20 years apart. Setting The surveys were performed at two Norwegian medical faculties in 1993 and 2015.

Participants One hundred and seventy-four first-year medical students in 1993 were compared with 169 students in 2015.

Main outcome measures Mental distress (Hopkins Symptom Checklist 5) and Mental Health Problems in Need of Treatment.

Results Mental distress increased from 1993 to 2015 $(p<0.001)$ due to a larger increase among female students, which seemed to be of clinical importance (Cohen's $d=0.63$ ). There was a significant gender difference in mental distress in 2015 ( $p=0.007)$, but not in 1993 . Independent factors associated with mental distress in 2015 were female sex $(p<0.001)$, low perceived social support from parents $(p=0.023)$ and low perceived social support from other friends $(p=0.048)$. Additional analyses showed that social support from friends was more important for female students than for their male peers. From 1993 to 2015, there was no significant increase in the proportion of female students reporting previous mental health problems in need of treatment $(21.3 \%$ vs $27.8 \%$ ), but we found a significant increase in helpseeking among those in need of treatment over these years from $30.0 \%(6 / 20)$ to $74.3 \%(26 / 35 ; p=0.003)$. Conclusions We found a significant increase in mental distress among female medical students over the past 20 years, but also a promising increase in help-seeking among those in need of treatment. The strong and important association between low social support and mental distress should urge both universities and students to maintain students' social life after entering medical school.

\section{INTRODUCTION}

Medical education is stressful and systematic reviews have estimated the prevalence of depressive symptoms among medical students to be $25 \%-28 \% .^{12}$ Still, the clinical importance of this with respect to professional help-seeking has been scarcely studied.

\section{Strengths and limitations of this study}

- Strengths of our study are the relatively high response rate 20 years ago and the use of measures that were well validated in previous studies.

- The effect size of the increase in mental distress among female students and the raised rate of professional help-seeking among those with treatment needs emphasise the clinical importance of this issue.

- This is a cross-sectional study, and we cannot infer causality with respect to the association between social support and mental distress.

- A limitation of our study is the lack of variables that play a more important role in young people's lives today than they did in 1993.

High scores of emotional distress in the first year of studies predict psychiatric morbidity in the third and final years, ${ }^{34}$ and a history of mental health problems preadmission is associated with an increased risk of problems during the curriculum. ${ }^{5}{ }^{6}$ Although several studies now find that mental distress among medical students may not be higher than that among other students, the consequences for both the students themselves and the patients they treat can be serious. ${ }^{7}$ Mental distress might contribute to the decreased empathy that has been found across the years of medical school. ${ }^{8}$ In addition, recurrent mental health problems are associated with course failures. ${ }^{9}$ We also know that mental distress can increase the risk of suicide, that rates of suicidal ideation are relatively high among medical students ${ }^{10}$ and that doctors commit suicide more often than do many other professionals. ${ }^{11}$ Despite these concerns, medical students in need of treatment are reluctant to seek help for mental health problems. ${ }^{1}{ }^{6}{ }^{12-14}$ Students report confidentiality concerns, personality, lack of information, doubts about treatment effectiveness and 
stigma related to mental health problems as barriers for accessing help. ${ }^{15}$ The current study aimed to identify the characteristics of medical students and other factors associated with high levels of depression and anxiety symptoms during their first year. The overall study goal was to contribute to improved early intervention programmes at medical schools and the development of curricula that promotes student well-being. ${ }^{16-18}$

International and Norwegian studies and reports show a general increase in levels of mental distress/anxiety and depressive symptoms in students and young adults over recent decades, mainly among women. ${ }^{119-22}$ The proportion of women entering medical school has steadily increased over the past 20 years. ${ }^{23}$ In Norway, there has been an increase from $55 \%$ in 1993 to $70 \%$ in $2015 .^{24}$ The prevalence of mental distress among students entering medical school might also be higher today compared with two decades ago. This affects the clinical importance and need for healthcare services for mental health problems among medical students today. In addition to gender, other individual and social contextual factors at entrance to medical school may impact mental distress. A previous Norwegian study found that younger age when starting medical school was a risk factor for severe depressive symptoms 15 years into a medical career. ${ }^{25}$ A Norwegian study found that different curriculums foster differences in negative attitudes and medical school-related stress, ${ }^{26}$ and such stress has been linked to mental health problems. ${ }^{6}$ There has been a steady increase in the number of people with higher education in Norway over the past decades, ${ }^{27}$ so the educational level of medical students' parents has also likely increased over the past 20 years. An association between fathers' level of education and mental distress has been reported in previous studies. ${ }^{28}$ Living accommodations have also been linked to mental distress; in a British study, compared with female students, male students seemed to experience more stress when living away from home. ${ }^{29}$ Hazardous drinking during medical school is a predictor for hazardous drinking later in life, ${ }^{30}$ but students with higher levels of selfesteem have also been found to show hazardous drinking patterns more often. ${ }^{31}$ However, the risky use of alcohol has been linked to mental distress, anxiety and depressive symptoms among Norwegian doctors, so it is generally pertinent to assess alcohol use in a study of mental health among medical students. ${ }^{32}$ Perceived social support, such as seeking advice and help from others, is an important stress-coping mechanism, ${ }^{33}$ and students experiencing low levels of social support report lower levels of wellbeing. ${ }^{34}$ Social support may be structural, such as living with a partner or friend, or functional, as in perceived social support from others; the latter seems of greatest importance with respect to emotional well-being. ${ }^{34} 35$ Personality traits such as neuroticism and low self-esteem are associated with emotional distress, depressive symptoms and even suicidal ideation in medical students. ${ }^{10} 36$ Such individual characteristics should be included when comparing mental health across different samples.
We also need to study the clinical importance of changes in mental distress. An increase or decrease in mental distress is difficult to evaluate in terms of clinical importance. Measures of mental distress need to be validated with respect to mental health disorders assessed by diagnostic interviews. Such mental distress 'caseness' is more clinically relevant. In addition, treatment needs and professional help-seeking are clinically relevant measures that can be used to validate changes in mental distress. ${ }^{6}$ Informing and encouraging students' help-seeking behaviour can lay the foundation for resilience, ${ }^{7}$ which is important for their studies. It can also help young doctors facing an increasing toll due to the higher workload, for example, from more clerical work. ${ }^{3738}$

We analysed data from two different Norwegian medical faculties based on a longitudinal, nationwide study of Norwegian students entering medical school in 1993 (The Longitudinal Study of Norwegian Medical Students and Doctors (NORDOC) ) and a cross-sectional study of Norwegian medical students on study conditions and health and well-being among Norwegian medical students (the STUDMED project) from 2015. A recent study of these student samples found a decrease in subjective well-being from 1993 to 2015. This decrease was apparent when comparing students in their first, middle or final year of medical school. ${ }^{34}$ Such knowledge may inform any changes in the mental health of students enrolled in medical school. Do first-year students in 2015 differ from those who began their studies in 1993 with regard to mental health problems?

We hypothesise an increase in mental distress among medical students, in accordance with the increase shown in recent reports of other young adults and students. ${ }^{19} 20$ We also believe that female students will report higher scores of mental distress, but we want to explore which factors that might contribute to this gender difference. In addition, we lack studies about the clinical importance of the increased levels of mental distress in Norwegian students. The main objectives of the current study are (1) to compare self-reported symptoms of mental distress (Hopkins Symptom Checklist 5 (SCL-5)) over a 20-year span among first-year students, particularly in terms of gender differences; (2) to identify characteristics of medical students with high levels of mental distress, including any clinical importance of such distress.

\section{METHODS \\ Setting}

The STUDMED and NORDOC surveys were conducted at two Norwegian universities to examine the effects of the study curriculum and learning conditions on contentment and mental health. All students' entry criteria were the same; all students were admitted from two equal quotas. The first quota included applicants up to age 21 years, based on their preuniversity grade point averages (GPAs). The second quota included older applicants admitted based on a total score composed of their GPAs 
plus points for age, military service, previous higher education and non-degree granting college attendance. Medical study extends over 6 years at both faculties, but these faculties have two different curriculum models. One faculty has a traditional curriculum with a preclinical phase for the first two years with limited patient contact, followed by a 4-year clinical phase (Fac trad). The other faculty has an integrated curriculum which involves a problem-based learning model and early patient contact, and integrated preclinical and clinical subjects (Fac int).

\section{Participants}

\section{STUDMED 2015}

In February and March of 2015, all medical students at the two faculties included in this study (Fac trad and Fac int) were invited to participate in STUDMED 2015 ( $\mathrm{n}=1635)$. The survey provided weekly digital and automatic reminders for those who had not yet responded. Prior to the study, the participants received information about the survey in their lecture rooms and on a Facebook page about the project. There was no reward for responders. The current study uses data of the first-year students who participated in STUDMED $2015(\mathrm{n}=169), 5$ months after enrolment. The response rate of the selected sample was $55 \%$ (96/174, $75 \%$ female respondents) at Fac trad and $60 \%(73 / 122,74 \%$ female $)$ at Fac int.

\section{NORDOC 1993}

To enable comparison, this study uses historical data from the same two faculties $(n=174)$ that participated in the NORDOC survey 1 month after enrolment in 1993. Prior to the NORDOC survey, all participants received information about the survey in the lecture rooms by the researchers, and received a music $\mathrm{CD}$ as a reward for responding. The total response rate for NORDOC in 1993 was $89 \% .{ }^{39}$ For the current study, the selected sample was: Fac trad, $\mathrm{n}=116,54 \%$ women; and Fac int, $\mathrm{n}=58,53 \%$ women.

\section{Measures}

Dependent variables

Mental distress was measured with a short version of the SCL-5 consisting of five items that score symptoms of depression and anxiety. ${ }^{40-42}$ The SCL-5 has previously been used in studies of Norwegian doctors, ${ }^{42}{ }^{43}$ and was included in both NORDOC and STUDMED. Students were asked to answer questions using a five-point scale with response options (1) 'not at all', (2) 'a little', (3) 'average', (4) 'quite a lot' and (5) 'very much' on the following items: 'How much during the last 14 days have you been bothered by...' (1) 'nervousness or shakiness inside', (2) 'feeling fearful', (3) 'feeling hopeless about the future', (4) 'feeling blue' and (5) 'worrying too much about things'. This short instrument accurately assesses symptoms of anxiety and depression. ${ }^{42}$ Mean score was calculated for the items, and dichotomised, with scores above 2.09 for men and 2.19 for women signifying students as SCL-5 cases and in potential need of treatment. ${ }^{40}$ Large population studies show an extremely skewed distribution of scores, with most subjects reporting no or few symptoms. Though cut-off levels for mental distress may appear low, they have been validated based on diagnostic interviews in a large population-based study; they are also gender specific, with lower levels required for men. ${ }^{40} 44$ These cut-off levels have also been used in a previous study of doctors seeking counselling for burn-out. ${ }^{43}$

Previous Mental Health Problems in Need of Treatment (MHPT) was used to validate the clinical importance of selfreported mental distress (present anxiety and depressive symptoms). This measure has previously been validated in young doctors and medical students. ${ }^{6546}$ Responders were asked: 'If you have ever had mental health problems, did you seek/receive help for them?'. The response alternatives were: (1) 'No mental health problems' (NORDOC)/'Not relevant' (STUDMED), (2) 'I have not had mental health problems of importance', (3) 'I have not sought help, although I have needed it', (4) 'Yes, I have consulted a general practitioner', (5) 'Yes, I have consulted a psychologist/psychiatrist' and (6) 'Yes, I have been admitted to a hospital psychiatric department'. The STUDMED survey also included a seventh alternative: 'Yes, I have accessed help through the faculty administration' (consulted on-campus help). Responses were dichotomised into 'no previous mental health problems in need of treatment': alternatives 1 and $2=0$, and 'yes, previous mental health problems in need of treatment': alternatives $3-6=1$. This was done consistent with previous studies of Norwegian medical students and doctors. ${ }^{645}$

\section{Independent variables}

Independent variables were chosen based on known associations with dependent factors, as described in the introduction.

Independent variables included female gender ( $1=$ female, $0=$ male), age (birth year) and faculty (Fac $\operatorname{trad}=0$, Fac int $=1$ ).

Mothers' and fathers' educational level was categorised into $0=$ from primary school up to college/university for less than 4 years and $1=$ university above 4 years.

Living accommodation consisted of two items: living alone ( $0=$ not living alone, $1=$ living alone) and living with friends $\left(0=\right.$ not living with friends, $1=$ living with friends) ${ }^{39}$

Social support was measured by three items of perceived social support: ${ }^{47}$ (1) 'How much is each of these people willing to go out of their way to do things to make your studies easier for you?', (2) 'How much is each of the following people willing to listen if you want to talk with them about your personal problems?' and (3) 'How much can each of these people be relied on when things get tough in your studies?'. Respondents were asked to state from whom they received different kinds of support on each item on a five-point scale from 1 ('never') to 5 ('very often/always') of the following people: (1) parents, (2) medical school friends, (3) other friends, (4) other family members, (5) partner and (6) faculty administration. Mean score was calculated for each category of the 
three items. A high total score indicates higher levels of social support.

Hazardous drinking was measured using an instrument that was previously validated among US college students and Norwegian medical students and doctors. ${ }^{30} 3148$ The participants were asked to respond to the question: 'Approximately how many times a year do you drink the amount of alcohol in one session equivalent to five bottles $(330 \mathrm{~mL})$ of beer $(4.5 \%)$, or one bottle of wine, or a half-bottle fortified wine or a quarter bottle of liquor (defined as $60 \mathrm{~g}$ of alcohol, and meant to cause intoxication)'. Responses were given on an eight-point scale from 1 ('none') to 8 ('almost every day'). The item was dichotomised as $0=1$ time per month or less and $1=2-3$ times per month or more. This cut-off is associated with harmful psychosocial consequences in US college students, and with increased use of medication for hypertension, dyspepsia and insomnia in Norwegian doctors. ${ }^{30}{ }^{48} \mathrm{We}$ assessed the same quantity of beverages and drinking frequencies and similar cut-offs among both men and women in 1993 and 2015.

Low general self-esteem was measured by Basic Character Inventory General Self-esteem subscale, ${ }^{31}{ }^{34}$ tapping into both low self-esteem and high self-esteem using eight items with responses from 1 (disagree) to 4 (agree). High mean sum scores indicate low general self-esteem. This subscale resembles closely the personality trait neuroticism. ${ }^{31}$

\section{Statistics}

Parametric differences were tested with Student's t-test and categorical differences with table analyses and $\chi^{2}$ test. Cohens' $d$ was used to estimate the effect size, or 'clinical significance' of parametric differences $(d$ : 0.02$0.49=$ small; $0.50-0.79=$ moderate; $\geq 0.8=$ large effects $).{ }^{49}$ Significance level was chosen to be $5 \%(p<0.05)$.

The following variables were used as predictors of high levels of mental distress: gender, age, faculty, living accommodation, social support, parents' level of education and hazardous drinking. We performed bivariate linear regression analysis for all independent variables in SCL-5. Multiple linear regression with the significant bivariate independent variables was performed with SCL- 5 as dependent variable (unstandardised beta $=\beta$ ). The significant adjusted predictors were also tested for gender interactions, in order to identify any differences in their impact between male and female students. The NORDOC and STUDMED samples were also tested for differences in low general self-esteem (independent samples t-test) to control for differences in individual trait susceptibility (or neuroticism) between samples.

\section{Missing data}

Missing data were excluded from the analyses. In NORDOC, the following variables among the first-year students had missing data: age (three missing), mother's level of education (three missing), father's level of education (two missing) and low self-esteem (four missing). In STUDMED, there were no missing data.

\section{Participant involvement}

Medical students have been involved in the planning of the project and the questionnaire. In addition, a medical student is first author of this manuscript.

\section{RESULTS}

\section{Changes in mental distress from 1993 to 2015}

The mean levels of SCL-5 increased among female students-1993: 1.64 (0.67) versus 2015: 2.17 (1.01), $\mathrm{t}=4.41, \mathrm{p}<0.001, d=0.63$, but among their male peers the increase was not significant (table 1). In 1993, no significant difference was observed between genders, but a gender difference as evidenced by mean SCL-5 levels was found in STUDMED (women: 2.17 (1.01), men: 1.73 (0.63), $\mathrm{p}=0.007)$. The prevalence of SCL-5 cases increased from $15.5 \%$ to $40.2 \%\left(\chi^{2}=26.16, \mathrm{p}<0.001\right)$. Among the female students, the increase went from $14.9 \%$ to $44.4 \%$ $\left(\chi^{2}=21.67, \mathrm{p}<0.001\right)$. We found no significant increase in SCL-5 caseness among men. There was a gender difference in low general self-esteem in both STUDMED (women 17.6 (5.19), men 15.5 (3.9), $\mathrm{t}=2.39, \mathrm{p}=0.018$ ) and NORDOC (women 16.9 (4.9), men 15.2 (4.0), $\mathrm{t}=2.43$, $\mathrm{p}=0.016$ ), but there was no difference in mean low selfesteem between the two samples in any of the genders. An additional finding was a substantial increase in hazardous drinking among female students from $7.4 \%$ in 1993 to $33.3 \%$ in $2015(\mathrm{p}<0.001$; table 1$)$.

\section{Predictors of mental distress}

The following variables were significant unadjusted predictors (table 2): female gender, faculty, hazardous drinking and perceived social support from parents, medical school friends, other friends and other family members. In the adjusted multiple regression model, the following predictors were significant: female gender ( $\beta=2.95$ (1.42 to 4.48$), p<0.001$ ), perceived social support from parents $(\beta=-0.91,(-0.34$ to -0.03$), p=0.023)$, and perceived social support from other friends $(\beta=-0.82$ ( -0.33 to -0.08$), \mathrm{p}=0.048)$. Explained variance was $17.8 \%$. There was a significant interaction with gender and perceived social support from other friends that also remained significant in the multiple regression $(\beta=2.15$ (0.78 to 3.51), $\mathrm{p}=0.002)$. This means that the effect of such social support was more important for the female students.

\section{Is the change in mental distress of clinical importance?}

The medium effect size $(d=0.52)$ of the increase in SCL-5 indicates that this can be of clinical importance, and we therefore validated SCL- 5 with the self-report of having previous MHPT. In 2015, 44.1\% of the SCL-5 cases reported previous MHPT $\left(\chi^{2}=22.61, \mathrm{p}<0.001\right)$. Among the female SCL-5 cases, $42.9 \%$ had previous MHPT $\left(\chi^{2}=11.43, \mathrm{p}=0.001\right)$ and among the male SCL-5 cases, $50 \%$ had MHPT $\left(\chi^{2}=13.89, \mathrm{p}<0.001\right)$. Table 3 shows that the rate of all students reporting previous MHPT increased from $16.7 \%$ in 1993 to $24.9 \%$ in $2015\left(\chi^{2}=5.55\right.$, 
Table 1 Overview of variables

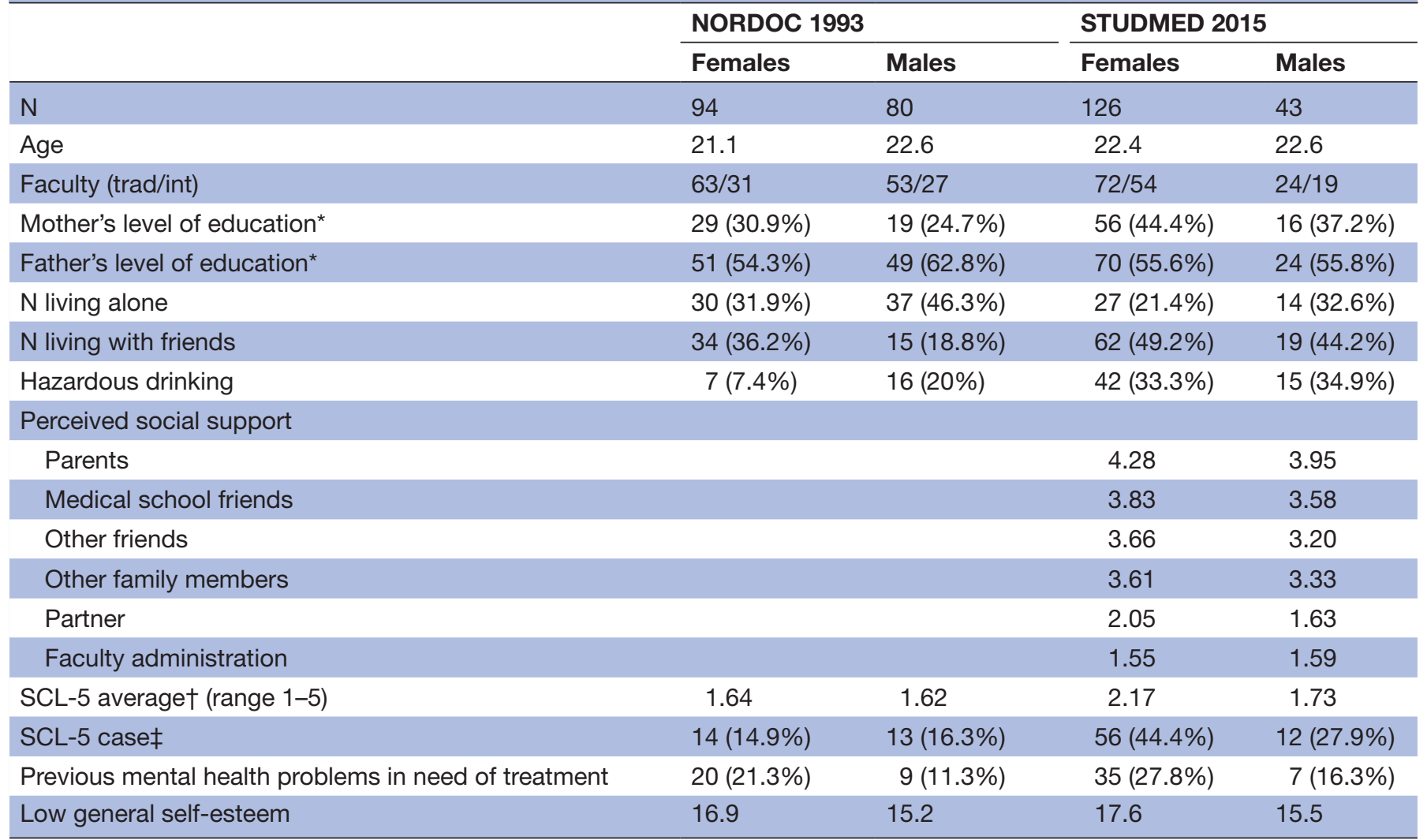

*Level of education $>4$ years of university.

†The mean levels of Hopkins Symptom Checklist 5 (SCL-5) in the total samples (both men and women) increased from 1993 (Longitudinal Study of Norwegian Medical Students and Doctors (NORDOC)) to 2015 (STUDMED): 1.63 (SD=0.64) versus 2.05 (0.95). $t=4.82, p<0.001$, $d=0.52$.

$\ddagger$ SCL-5 case $=$ women $>2.19$, men $>2.09$.

$\mathrm{p}=0.019$; table 3$)$. When separated by gender, there was no significant increase in previous MHPT (female students, $21.3 \%$ vs $27.8 \%$; male students, $11.3 \%$ vs $16.3 \%$ ).

Comparison of help-seeking among those reporting previous MHPT shows that $69.0 \%$ of these students in 2015 had at some point accessed help versus only $37.9 \%$ in $1993\left(\chi^{2}=5.55, \mathrm{p}=0.019\right)$. There was a significant increase in the prevalence of help-seeking among the female students reporting previous MHPT from $30.0 \%$ to $74.3 \%\left(\chi^{2}=8.52, \mathrm{p}=0.004\right)$, but we found no such increase among the male students.

\section{DISCUSSION}

\section{Statement of principal findings}

This study finds that mental distress (measured by SCL- 5 average) among first-year medical students has increased over the past 20 years for both female and male students, though this change was only significant among females. Female gender and low social support were independently associated with mental distress. The effect size among female students $(d=0.63)$ suggests an increase of clinical importance, and so does the number of SCL- 5 cases with mental health treatment needs. There was a substantial increase in help-seeking for mental health treatment needs among the female medical students compared with those 20 years ago. In addition, we found a significant increase in hazardous drinking among female students, and a narrowing of the gender gap.

Forty-four per cent of the students categorised as SCL-5 cases reported previous MHPT, which emphasises the clinical importance of this caseness. This finding seems to be promising because there was an increase in helpseeking among the female students who reported a need for treatment; that is, almost three out of four female students had sought help in 2015, whereas about one in three had sought help 20 years earlier. This may indicate a lower threshold for and maybe easier access to seeking help among the young adults with treatment needs.

\section{Strengths and weaknesses of the study}

Comparing data from the STUDMED sample with representative data from the same two faculties studied 20 years earlier gives strength to this original study. It would have been preferable with higher response rates in the STUDMED sample; the low number of male respondents might give rise to type II errors (false-negative findings). However, the gender ratio in both STUDMED and NORDOC is representative for the actual ratio at the two 
Table 2 Results of multiple regression analysis of mental distress (Hopkins Symptoms Checklist 5) in STUDMED, significant estimates in bold

\begin{tabular}{|c|c|c|c|c|c|c|}
\hline & \multicolumn{3}{|c|}{ Unadjusted model } & \multicolumn{3}{|c|}{ Adjusted model } \\
\hline & $\beta$ & $\mathrm{Cl}$ & $P$ value & $\beta$ & $\mathrm{Cl}$ & $P$ value \\
\hline Female gender & 2.23 & 0.61 to 3.85 & 0.007 & 2.95 & 1.42 to 4.48 & $<0.001$ \\
\hline Age & 0.02 & -0.23 to 0.28 & 0.865 & -0.13 & -0.07 to 0.02 & 0.301 \\
\hline Faculty ${ }^{*}$ & 1.49 & 0.05 to 2.93 & 0.043 & 1.22 & -0.02 to 0.51 & 0.072 \\
\hline Mother's level of education & 0.63 & -0.83 to 2.09 & 0.393 & & & \\
\hline Father's level of education & -0.74 & -1.63 to 1.28 & 0.814 & & & \\
\hline Living alone & -0.77 & -2.45 to 0.91 & 0.368 & & & \\
\hline Living with friends & 0.37 & -1.08 to 1.81 & 0.616 & & & \\
\hline Hazardous drinking & -1.89 & -3.40 to 0.39 & 0.014 & -1.28 & -0.54 to 0.03 & 0.075 \\
\hline \multicolumn{7}{|l|}{ Perceived social support } \\
\hline Parents & -1.20 & -1.85 to 0.56 & $<0.001$ & -0.91 & -0.34 to -0.03 & 0.023 \\
\hline Medical school friends & -1.28 & -2.08 to -0.48 & 0.002 & -0.56 & -0.30 to 0.08 & 0.238 \\
\hline Other friends & -1.16 & -1.82 to -0.50 & 0.001 & -0.82 & -0.33 to -0.00 & 0.048 \\
\hline Other family members & -0.79 & -1.37 to -0.21 & 0.008 & 0.21 & -0.11 to 0.19 & 0.593 \\
\hline Partner & 0.13 & -0.19 to 0.46 & 0.419 & & & \\
\hline Faculty administration & -0.38 & -0.93 to 0.17 & 0.174 & & & \\
\hline
\end{tabular}

${ }^{*}$ Fac trad=0, Fac int $=1$

faculties in 2015 and 1993, respectively, which minimises the risk for gender bias.

Self-reporting of symptoms is not as valid as an observed clinical diagnosis by interview, but the effect size and increase in seeking professional help underscore that this is a problem of clinical importance among female students entering medical schools today. Furthermore, self-reported treatment need is not a valid measure of objective treatment need, and is thus a possible study weakness, since many of the students reporting such needs may have minor health problems that are less important. The STUDMED sample was approached months later in their first year compared with the NORDOG sample. Still, mental distress (anxiety and depressive symptoms) is influenced by factors beyond school-related stress; therefore, we believe that previous treatment needs and help-seeking may refer to a past much longer than a few months. A major limitation is the cross-sectional design; the statistical predictor model cannot infer any causality.

\section{Strengths and weaknesses in relation to other studies}

Strengths of our study are the relatively high response rate 20 years ago and our use of measures that were well validated in previous studies.

The current original findings in medical students concur with Norwegian reports about a steady increase in depressive symptoms among adolescent girls and female students over the past 10-20 years. ${ }^{19} 20$ This indicates that our findings are not isolated to just medicine, but rather indicate a trend in society in general. A previous American review of emotional distress among medical students from 2006 found higher levels of distress than in the general population, but with no convincing higher levels of distress among medical students compared with those among other college and university students. ${ }^{36} \mathrm{~A}$ review from 2013 found that the prevalence of depressive disorders among university students in general was significantly higher than that among the general population. ${ }^{50}$ Sixteen of the included 24 studies reported gender differences, the majority finding a higher prevalence among female compared with male students. This indicates that a higher rate of female university students suffers from mental health problems. We can only speculate about the assessment of mental disorders among our participants, and diagnostic interviews are still lacking in studies of medical students and doctors. Still, a recent Irish study found that a substantial portion (39\%) of medical students screened positive for depression. ${ }^{51}$ Therefore, such distress can interfere with the careers of medical students and young doctors. We have no normative data on SCL-5 caseness among other Norwegian students. A study comparing all Norwegian doctors in 1993 versus doctors seeking intervention-based burn-out counselling (Villa Sana) in 2003 found the following rates among female doctors: $18 \%$ versus $73 \%$, respectively. ${ }^{40}$ Our female students in 2015, 44\%, appear to fall between these estimates.

Our findings are in keeping with an American national study that found an increase in professional help-seeking among adolescents and young adults from 2005 to $2014{ }^{21}$ The increase in professional help-seeking may be due to reduced stigma during the last decades, and this is a positive trend. On the other hand, the mentioned Irish study showed that increased emotional exhaustion and decreased academic efficacy reduce the willingness to seek help among medical students, and the factors related to help-seeking among them should be further studied..$^{51}$ 


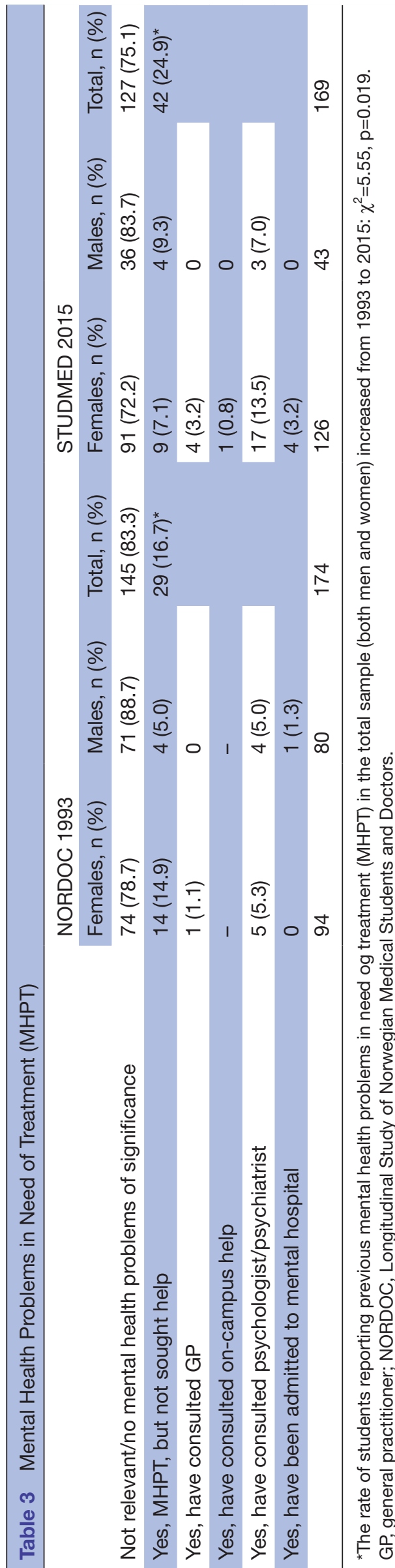

We found no difference in levels of self-esteem among the female students of 1993 and those of 2015. This suggests that the female population of 2015 does not differ in terms of trait neuroticism from that of 1993, and factors other than a vulnerable trait may be of importance. A limitation of our study is the lack of variables that play a more important role in young people's lives today than they did in 1993. Social media is often referred to as a possible explanation of increased distress, and an association was found between time spent on social media and symptoms of anxiety. ${ }^{52}$ The use of social media and cyber bullying is more common among female adolescents than among their male peers. ${ }^{5354}$ Increased performance pressure affects girls more than boys because of an additional pressure to maintain a more traditional feminine gender role. ${ }^{55}$

Lower levels of social support from friends outside of medical school, as well as low support from parents, were both independently associated with mental distress. This is a cross-sectional study, and we do not know whether social support protects against mental deterioration or whether those with high levels of mental distress experience less social support. Nevertheless, this finding is consistent with other studies that have emphasised the role of functional or perceived social support for emotional well-being, at the expense of structural social support, that is, the variable living accommodation in our study. ${ }^{35}$ A prospective study on first-year medical students in Germany found that high levels of perceived social support before entering medical school were not associated with better mental health during the end of their first term, suggesting that the loss of one's social support system throughout the first term was of more importance than social support before enrolment. ${ }^{55}$ American prospective studies among medical students have found that social support increases resilience against burn-out, and low social support is a prognostic factor with respect to depressive symptoms later in medical school. ${ }^{567}$ In addition, it was found that medical students participate less in activities with friends outside medical school and with relatives after enrolment. ${ }^{58}$ Therefore, encouraging medical students to prioritise activities with friends and family is crucial. Studies of Norwegian medical students have revealed that social support may be important for enduring positive mental health, such as subjective well-being. ${ }^{34} 39$

Unexpectedly, there was an unadjusted association between high levels of mental distress and low levels of hazardous drinking; this association also approached significance in the adjusted model. One reason for this may be social isolation, since we know that social gatherings among today's students often include heavy drinking. This may exclude some groups of students, for example, those from other ethnic or religious backgrounds. It is noteworthy that there was a substantial increase in hazardous drinking, from $7 \%$ to $33 \%$, among the female students during the two decades between 1993 and 2015, almost up to similar rate as with male students (35\%). The narrowing of the gender gap with respect to drinking is consistent with other studies, but it is contrary to the gender difference in drinking levels among medical students in an American study. ${ }^{59}$ Since we assessed the consumption 
of a similar number of beverages among men and women (five in one occasion), we may have underestimated the levels of hazardous drinking among female students. The consequences of increased drinking among female medical students in Norway should be studied further.

There was a significant unadjusted effect of faculty and a close to significant effect in the adjusted analysis. Post hoc analyses showed that each of the variables about social support from parents, medical school friends and siblings mediated the effect of faculty. As might have been expected, there was no effect of the different curricula during these students' first years.

\section{Meaning of the study: possible explanations and implications for clinicians and policy-makers}

The current study shows that there has been a significant increase in mental distress among female medical students over the past 20 years, and the effect size of this increase in distress and raised rate of professional helpseeking among those with treatment needs emphasise the clinical importance of this issue.

The findings of the association between low social support and mental distress should urge universities to implement strategies that encourage students to maintain their social life. Continuous support and access to professional help should be available for those new students with mental health treatment needs. In addition, wellbeing curriculums for students have been implemented in several US medical schools, and such preventive measures may be of great value for first-year students. ${ }^{60}$

\section{Unanswered questions and future research}

This study does not reveal what makes life more bothersome for young people today. The role of social media in young people's lives today should be investigated further, as it could both be a source of unhealthy comparisons as well as a new platform for being social and making friends. The predictive validity of social support during the enrolment year to medical school remains to be studied in a prospective study. The course and trends of mental distress and help-seeking among today's students and the impact of this on their performance during medical school has not yet been studied using a longitudinal design.

\section{CONCLUSION}

Herein, we found a higher level of mental distress and more previous professional help-seeking for mental health problems among first-year female medical students in 2015 compared with 1993; this increase seems to be of clinical importance. Therefore, social support from both parents and friends appear to be independent factors linked to first-year medical students' mental distress.

Correction notice This article has been corrected since it was first published. The funding statement has been corrected.

Contributors NR and RT conceived the study in collaboration with LTL. LTL and RT planned and wrote the protocol for the STUDMED project. NR and RT performed the data analyses in the present study. KIR contributed with valuable references, and was heavily involved in the revision. All authors participated in writing and finalising the present manuscript.

Funding The NORDOC project was funded by the Norwegian Research Council and the Norwegian Medical Association. STUDMED 2015 was funded by St Olav University Hospital in Trondheim, Norway.

Competing interests None declared.

Patient consent for publication Not required.

Ethics approval NORDOC was initially approved by the Norwegian National Data Inspectorate and performed according to the guidelines of the Regional Committee for Medical and Health Research Ethics of Southern Norway (later approvals: 2009/788a REK South East A, and 2013/1585 REK South East C). STUDMED 2015 was approved by the Regional Committee for Medical and Health Research Ethics of Central Norway (2013/2408 REK Central).

Provenance and peer review Not commissioned; externally peer reviewed.

Data availability statement Data are available upon reasonable request. All data and materials are available upon request to the principle investigator (last author).

Open access This is an open access article distributed in accordance with the Creative Commons Attribution Non Commercial (CC BY-NC 4.0) license, which permits others to distribute, remix, adapt, build upon this work non-commercially, and license their derivative works on different terms, provided the original work is properly cited, appropriate credit is given, any changes made indicated, and the use is non-commercial. See: http://creativecommons.org/licenses/by-nc/4.0/.

ORCID iD

Nora Ruud http://orcid.org/0000-0002-3434-5328

\section{REFERENCES}

1 Rotenstein LS, Ramos MA, Torre M, et al. Prevalence of depression, depressive symptoms, and suicidal ideation among medical students: a systematic review and meta-analysis. JAMA 2016;316:2214-36.

2 Puthran R, Zhang MWB, Tam WW, et al. Prevalence of depression amongst medical students: a meta-analysis. Med Educ 2016:50:456-68.

3 Dahlin ME, Runeson B. Burnout and psychiatric morbidity among medical students entering clinical training: a three year prospective questionnaire and interview-based study. BMC Med Educ 2007;7:6.

4 Guthrie E, Black D, Bagalkote H, et al. Psychological stress and burnout in medical students: a five-year prospective longitudinal study. J R Soc Med 1998;91:237-43.

5 Yates J, James D, Aston I. Pre-existing mental health problems in medical students: a retrospective survey. Med Teach 2008;30:319-21.

6 Midtgaard M, Ekeberg Øivind, Vaglum P, et al. Mental health treatment needs for medical students: a national longitudinal study. Eur Psychiatry 2008;23:505-11.

7 Dyrbye LN, Thomas MR, Shanafelt TD. Medical student distress: causes, consequences, and proposed solutions. Mayo Clin Proc 2005;80:1613-22.

8 Hojat M, Gonnella JS, Mangione S, et al. Empathy in medical students as related to academic performance, clinical competence and gender. Med Educ 2002;36:522-7.

9 Yates J. When did they leave, and why? A retrospective case study of attrition on the Nottingham undergraduate medical course. BMC Med Educ 2012;12.

10 Tyssen R, Vaglum P, Grønvold NT, et al. Suicidal ideation among medical students and young physicians: a nationwide and prospective study of prevalence and predictors. J Affect Disord 2001;64:69-79.

11 Hem E, Haldorsen T, Aasland OG, et al. Suicide rates according to education with a particular focus on physicians in Norway 19602000. Psychol Med 2005;35:873-80.

12 Givens JL, Tjia J. Depressed medical students' use of mental health services and barriers to use. Acad Med 2002;77:918-21.

13 Tjia J, Givens JL, Shea JA. Factors associated with undertreatment of medical student depression. J Am Coll Health 2005;53:219-24.

14 Gaspersz R, Frings-Dresen MHW, Sluiter JK. Prevalence of common mental disorders among Dutch medical students and related use and need of mental health care: a cross-sectional study. Int J Adolesc Med Health 2012;24:169-72. 
15 Hunt J, Eisenberg D. Mental health problems and help-seeking behavior among college students. J Adolesc Health 2010;46:3-10.

16 Wright B, Richmond Mynett J, Mynett J. Training medical students to manage difficult circumstances- a curriculum for resilience and resourcefulness? BMC Med Educ 2019;19:280.

17 Slavin SJ, Schindler DL, Chibnall JT. Medical student mental health 3.0: improving student wellness through curricular changes. Acad Med 2014;89:573-7.

18 Reed DA, Shanafelt TD, Satele DW, et al. Relationship of pass/ fail grading and curriculum structure with well-being among preclinical medical students: a multi-institutional study. Acad Med 2011;86:1367-73.

19 Bakken A. Ungdata. National results 2018, NOVA report 8/18. Oslo: NOVA, 2018

20 Knapstad MHO, Sivertsen B. Studentenes Helse- og Trivselsundersøkelse 2018. [Students' Health and Wellbeing Study 2018]. Report. Oslo: SiO (Studentsamskipnaden i Oslo og Akershus), 2018.

21 Mojtabai R, Olfson M, Han B. National trends in the prevalence and treatment of depression in adolescents and young adults. Pediatrics 2016;138:e20161878.

22 Balázs J, Miklósi M, Keresztény A, et al. Adolescent subthresholddepression and anxiety: psychopathology, functional impairment and increased suicide risk. J Child Psychol Psychiatry 2013;54:670-7.

23 Moberly T. Number of women entering medical school rises after decade of decline, 2018. Available: https://www.bmj.com/bmj/ section-pdf/959692? path=/bmj/360/8138/Careers.full.pdf [Accessed 24 Oct 2019].

24 Samordnaopptak. The Norwegian universities and colleges admission service (NUCAS). Available: https://www.samordnaopptak. no/info/om/sokertall/ [Accessed 24 Oct 2019].

25 Støen Grotmol K, Gude T, Moum T, et al. Risk factors at medical school for later severe depression: a 15-year longitudinal, nationwide study (NORDOC). J Affect Disord 2013;146:106-11.

26 Gude T, Hjortdahl P, Anvik T, et al. Does change from a traditional to a new medical curriculum reduce negative attitudes among students? A quasi-experimental study. Med Teach 2005;27:737-9.

27 Norway S. Befolkningens utdanningsnivå, 2015.

28 Nerdrum P, Rustøen T, Rønnestad MH. Student psychological distress: a psychometric study of 1750 Norwegian 1st-year undergraduate students. Scand J Educ Res 2006;50:95-109.

29 Moffat KJ, McConnachie A, Ross S, et al. First year medical student stress and coping in a problem-based learning medical curriculum. Med Educ 2004;38:482-91.

30 Mahmood Jl, Grotmol KS, Tesli M, et al. Risk factors measured during medical school for later hazardous drinking: a 10-year, longitudinal, nationwide study (NORDOC). Alcohol Alcohol 2016;51:71-6.

31 Tyssen R, Vaglum P, Aasland OG, et al. Use of alcohol to cope with tension, and its relation to gender, years in medical school and hazardous drinking: a study of two nation-wide Norwegian samples of medical students. Addiction 1998;93:1341-9.

32 Mahmood JI, Støen Grotmol K, Tesli M, et al. Contextual factors and mental distress as possible predictors of hazardous drinking in Norwegian medical doctors: a 15-year longitudinal, nationwide study. Eur Addict Res 2017;23:19-27.

33 Bamuhair SS, Al Farhan Al, Althubaiti A, et al. Sources of stress and coping strategies among undergraduate medical students enrolled in a problem-based learning curriculum. J Biomed Educ 2015;2015:1-8.

34 Sletta C, Tyssen R, Løvseth LT. Change in subjective well-being over 20 years at two Norwegian medical schools and factors linked to well-being today: a survey. BMC Med Educ 2019;19:45.

35 Heaney CA, Israel BA. Social networks and social support. In: Glanz K, Rimer BK, Viswanath K, eds. Health behavior and health education: theory, research and practice. 4th edn. San Francisco, CA: John Wiley \& Sons, Inc., 2009: 189-210.

36 Dyrbye LN, Thomas MR, Shanafelt TD. Systematic review of depression, anxiety, and other indicators of psychological distress among U.S. and Canadian medical students. Acad Med 2006;81:354-73.

37 Royal College of Physicians. Being a junior doctor: experiences from the front line of the NHS, 2016. Available: https://www.rcplondon.ac. uk/guidelines-policy/being-junior-doctor [Accessed 24 Oct 2019].
38 Rao SK, Kimball AB, Lehrhoff SR, et al. The impact of administrative burden on academic physicians: results of a hospital-wide physician survey. Acad Med 2017;92:237-43.

39 Kjeldstadli $K$, Tyssen $R$, Finset $A$, et al. Life satisfaction and resilience in medical school-a six-year longitudinal, nationwide and comparative study. BMC Med Educ 2006;6:48.

40 Rø KEI, Gude T, Aasland OG. Does a self-referral counselling program reach doctors in need of help? A comparison with the general Norwegian doctor workforce. BMC Public Health 2007;7:36.

41 Strand BH, Dalgard OS, Tambs K, et al. Measuring the mental health status of the Norwegian population: a comparison of the instruments SCL-25, SCL-10, SCL-5 and MHI-5 (SF-36). Nord J Psychiatry 2003;57:113-8

42 Tambs K, Moum T. How well can a few questionnaire items indicate anxiety and depression? Acta Psychiatr Scand 1993;87:364-7.

$43 \mathrm{Rø} \mathrm{KEl,} \mathrm{Gude} \mathrm{T,} \mathrm{Tyssen} \mathrm{R,} \mathrm{et} \mathrm{al.} \mathrm{Counselling} \mathrm{for} \mathrm{burnout} \mathrm{in}$ Norwegian doctors: one year cohort study. BMJ 2008;337:a2004.

44 Sandanger I, Moum T, Ingebrigtsen G, et al. The meaning and significance of caseness: the Hopkins symptom Checklist-25 and the composite international diagnostic interview. II. Soc Psychiatry Psychiatr Epidemiol 1999;34:53-9.

45 Tyssen R, Røvik JO, Vaglum P, et al. Help-seeking for mental health problems among young physicians: is it the most ill that seeks help? - A longitudinal and nationwide study. Soc Psychiatry Psychiatr Epidemiol 2004;39:989-93.

46 Tyssen R, Vaglum P, Gronvold NT, et al. The impact of job stress and working conditions on mental health problems among junior house officers. A nationwide Norwegian prospective cohort study. Med Educ 2000;34:374-84.

47 Caplan RD, Cobb S, French JRP, et al. Job demands and worker health - Main effects and occupational differences. Ann Arbor: Survey Research Center, Institute of Social Research, University of Michigan, 1980.

48 Wechsler H, Davenport A, Dowdall G, et al. Health and behavioral consequences of binge drinking in college. A national survey of students at 140 campuses. JAMA 1994;272:1672-7.

49 Cohen J. Statistical power analysis for behavioral sciences. 2nd edn. Hillsdale: Lawrence Erlbaum Associates, 1988.

50 Ibrahim AK, Kelly SJ, Adams CE, et al. A systematic review of studies of depression prevalence in university students. $J$ Psychiatr Res 2013;47:391-400.

51 Fitzpatrick O, Biesma R, Conroy RM, et al. Prevalence and relationship between burnout and depression in our future doctors: a cross-sectional study in a cohort of preclinical and clinical medical students in Ireland. BMJ Open 2019;9:e023297.

52 Vannucci A, Flannery KM, Ohannessian CM. Social media use and anxiety in emerging adults. J Affect Disord 2017;207:163-6.

53 Sletten MA, Bakken A. Psykiske helseplager blant ungdom -tidstrender OG samfunnsmessige forklaringer. en kunnskapsoversikt OG en empirisk analyse. nova notat 4/16. Oslo: NOVA, 2016.

54 Kessel Schneider S, O'Donnell L, Smith E. Trends in Cyberbullying and school bullying victimization in a regional census of high school students, 2006-2012. J Sch Health 2015;85:611-20.

55 Kötter T, Tautphäus Y, Obst KU, et al. Health-Promoting factors in the freshman year of medical school: a longitudinal study. Med Educ 2016;50:646-56.

56 Dyrbye LN, Power DV, Massie FS, et al. Factors associated with resilience to and recovery from burnout: a prospective, multi-institutional study of US medical students. Med Educ 2010;44:1016-26.

57 Dyrbye LN, Wittlin NM, Hardeman RR, et al. A prognostic index to identify the risk of developing depression symptoms among U.S. medical students derived from a national, four-year longitudinal study. Acad Med 2019;94:217-26.

58 Strayhorn G. Expectations versus reality, social support, and the well-being of medical students. Behav Med 1989;15:133-9.

59 Merlo LJ, Curran JS, Watson R. Gender differences in substance use and psychiatric distress among medical students: a comprehensive statewide evaluation. Subst Abus 2017;38:401-6.

60 Dyrbye LN, Sciolla AF, Dekhtyar M, et al. Medical school strategies to address student well-being: a national survey. Acad Med 2019;94:861-8 